\title{
CFD Study of Rewetting Nuclear Fuel Rod Bundle by Zig-Zag Jet Impingement
}

\author{
Ajoy Debbarma* and Krishna Murari Pandey \\ Department of Mechanical, National Institute of Technology Silchar, Silchar - 788010, Assam, India; \\ ajoy@debbarma.me, beriljoyme24@gmail.com, kmpandey2001@yahoo.com
}

\begin{abstract}
Rewetting is the process of re-establishment of coolant contact with hot surfaces. The present numerical analysis of rewetting nuclear fuel rod are conducted with a proposed zigzag jet direction model in AHWR. Further analysis studied with various jet diameters; $2 \mathrm{~mm}, 3 \mathrm{~mm}$ and $4 \mathrm{~mm}$. The computational domain for simulation; single sector of AHWR, with a vertical section of $542 \mathrm{~mm}$. The domain has 9 fuel rods arranged in three concentric ring. This work has carried out in ANSYS CFX 14.0 packages, with transient two-phase flow. The turbulences validation exercise found SST model, with fairly prediction of experimental data. The wall temperature profile shows irregular and uneven across the surface. The wetting delay at any inlet section is negligible and it got increases in the position away from the inlet section. The wall temperature increases in the section where void sustainability is longer, it is observed with small jet diameter. Overall, the zigzag jet direction has a very responsive information compared to existing model. The present result also evicted that increased in jet diameter, the rewetting temperature and wetting delay reduce significantly.
\end{abstract}

Keywords: Advanced Heavy Water Reactor, Rewetting Temperature, Shear Stress Turbulence, Wetting Delay, Zig-Zag Jet Impingement,

\section{Introduction}

Rewetting of rod bundle during Loss of Coolant Accident (LOCA) is a process which a injected coolant wets a hot surface by displacing vapor formation. As the rod bundle temperature is high, it may not get wet immediately with coolant contact. These have to be re-wetted within a stipulated period. For such scenario Emergency Core Cooling System (ECCS) become operative to cool down rod bundle.

Literature survey report that the rewetting phenomena depend on coolant flow rate, initial wall temperature and liquid sub-cooled etc. ${ }^{1}$ reported that the delay time is a particularly strong function of water sub-cooling, jet velocity, heat generation rate, surface temperature, jet impact angle and thermal conductivity. Unlikely surface finish and rod size did not affect delay time. ${ }^{2}$ Studied the effect of the coolant vapor quality on the rewetting process in bottom flooding. ${ }^{3}$ Presented an experimental and theoretical study of flow and heat transfer regimes during quenching of a heated vertical channel. ${ }^{4}$ Described wetting delay (resident time), which is a function of block material, jet velocity subcooling, initial wall temperature and jet velocity. ${ }^{5}$ Study the characteristics of heat transfer by water jet at atmospheric pressure. ${ }^{6,7}$ Report an experimental study of boiling heat transfer during quenching of a cylindrical copper disk. ${ }^{8,9}$ Investigate the effect of jet diameter and nozzle geometry. Sahu et al. ${ }^{10}$ Consider the effect of the several coolant injection system. Patil et al. ${ }^{11}$ Present the experimental result of cooling Advanced Heavy Water Reactor (AHWR) rod bundle. Kumar et al. ${ }^{12,13}$ Numerically study the circumferential conduction of rod and found significant with radial jet which influence on circumferential rewetting of a fuel pin. Debbarma and Pandey ${ }^{14}$, also formulate the numerical analysis using ANSYS CFX 14.0 code for the flow effect and jet diameter in rewetting AHWR fuel cluster. Further extended work also describe the variation of jet direction model ${ }^{15}$. The present numerical analysis aimed to bring out rewetting pattern in rod bundle by zigzag jet direction. In the present paper, most emphasis has given on the effect of jet diameter and jet direction for radial jet

\footnotetext{
*Author for correspondence
} 
impingement in an AHWR fuel rod bundle. This reactor is an Indian proposed third stage water based reactor with a heavy water moderator, having unique concept of radial jet impingement Emergency Core cooling System (ECCS).

\section{Computational Physical Models}

\subsection{Computational Domain}

AHWR fuel bundle is housed in the pressure tube, three concentric rings arranged for 54 rods of $3.5 \mathrm{~m}$ vertical height ${ }^{14}$. The fuel assembly contains 54 rods of $11.2 \mathrm{~mm}$ diameter is designed with a central coolant tube. The central water tube has six holes of 1.5-2 mm diameter is proposed in AHWR fuel assembly and arranged such that each sector contains one hole. Each jet placed at 13 different vertical axial locations with a pitch of 271

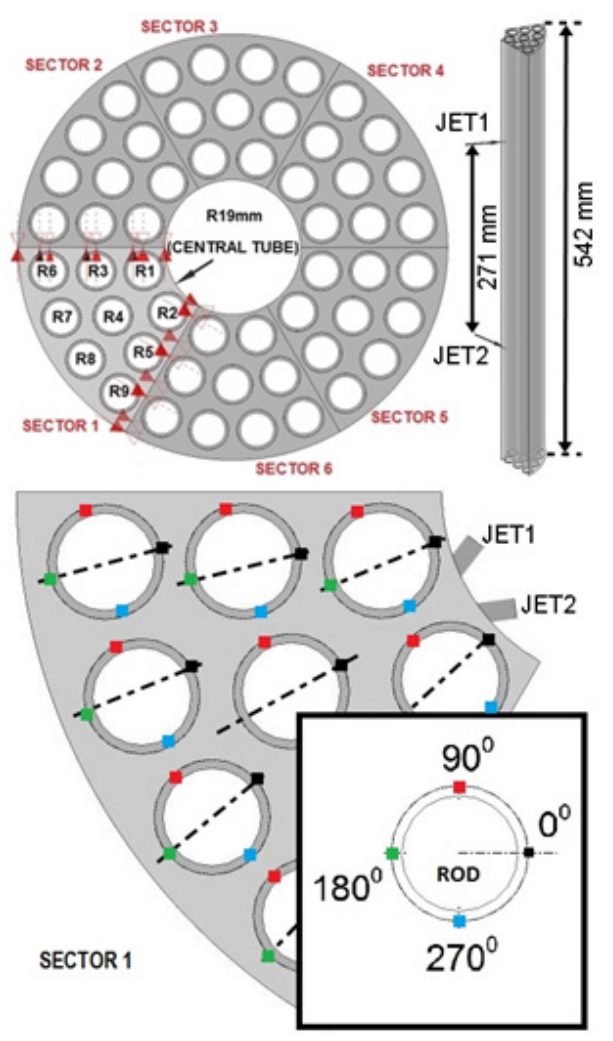

Figure 1. Fuel assembly with Zig-Zag jet impingement.

different vertical axial locations with a pitch of $271 \mathrm{~mm}$, for injecting emergency coolant water into the rod bundle.

The present computational investigation used single sector (1/6th) of the AHWR fuel cluster with Zig-Zag $\mathrm{mm}$, for injecting emergency coolant water into the rod bundle.

The present computational investigation used single sector (1/6th) of the AHWR fuel cluster with Zig-Zag jet directions. The computational model is presented in Figure 1. For simplicity of simulation, the vertical height of $542 \mathrm{~mm}$ with two jets is considered. Both the JET1 and JET2 are placed in the vertical location of $406.5 \mathrm{~mm}$ and $135.5 \mathrm{~mm}$ respectively. The two walls of the fluid domain adjacent to other sectors are considered as symmetric wall. The solid domain annular clad with outer and inner diameters is $11.2 \mathrm{~mm}$ and $9.2 \mathrm{~mm}$ respectively shown in Figure 1. In present proposed model the modified ZigZag jet direction, JET1 directed through in between the ROD4 - ROD5 and JET2 through in between ROD4 ROD3.

\subsection{Numerical Method}

The ensemble-averaged balance equations of mass, momentum and energy which govern each phase are as follows for homogeneous multiphase flow in CFX.

$$
\begin{aligned}
& \frac{\partial}{\partial t}\left(r_{a} \rho_{a}\right)+\nabla \cdot\left(r_{a} \rho_{a} U_{a}\right)=\sum_{\beta=1}^{N p} \Gamma_{a \beta} \\
& \frac{\partial}{\partial t}\left(r_{a} \rho_{a} U_{a}\right)+\nabla \cdot\left(r_{a}\left(\rho_{a} U_{a} \otimes U_{a}\right)\right) \\
& =-r_{a} \nabla p_{a}+r_{a} \rho_{a} g+\nabla \cdot\left(r_{a} \mu_{a}\left(\nabla U_{a}+\left(\nabla U_{a}\right)^{T}\right)\right) \\
& +\sum_{\beta=1}^{N p}\left(\Gamma_{a \beta}^{+} U_{\beta}-\Gamma_{\beta a}^{+} U_{a}\right)+\sum_{\beta=1}^{N p} M_{a \beta} \\
& \frac{\partial}{\partial t}\left(r_{a} \rho_{a} e_{a}\right)+\nabla \cdot\left(r_{a} \rho_{a} U_{a} e_{a}\right) \\
& =\nabla \cdot\left(r_{a} \lambda_{a} T_{a}\right)+r_{a} \tau_{a}: \nabla U_{a}+S_{E a}+\sum_{\beta=1}^{N p} Q_{a \beta} \\
& +\sum_{\beta=1}^{N}\left(\Gamma_{a \beta}^{+} e_{\beta}-\Gamma_{\beta a}^{+} e_{a s}\right)
\end{aligned}
$$

Where $r_{\alpha}, \rho_{a}, p_{a}, U_{a}, T_{a}$ and $\mathrm{e}_{\alpha}$ are the volume fraction, density, pressure, velocity, temperature and internal energy of phase $\alpha$ respectively and $\mathrm{N}_{\mathrm{p}}$ is the number of phases. $\Gamma_{\alpha \beta}$ is the mass flow rate per unit volume from $\beta$ to phase $\alpha$. The mechanism of heating the liquid phase is called quenching and quenching heat transfer to the liquid phase in the area of influence of the vapor phase is modeled using a quenching heat 
transfer coefficient (neglecting radiation):

$$
h_{q}=0.62\left[\frac{k_{v}^{3} \rho_{v}\left(\rho_{l}-\rho_{v}\right) g \cdot h_{f g}}{\mu_{v} D_{o} \Delta T}\left(1+\frac{0.4 c_{p v} \Delta T}{h_{f g}}\right)\right]^{1 / 4}
$$

The $k$ - $\omega$ based SST model accounts for the transport of the turbulent shear stress and gives highly accurate predictions of the onset and the amount of flow separation. Homogeneous turbulence as follows:

$\mathrm{k}$ - Equation:

$$
\begin{aligned}
& \frac{\partial(\rho \lg k)}{\partial t}+\frac{\partial}{\partial x_{j}}\left(\rho_{\lg } U_{j} k\right) \\
& =\frac{\partial}{\partial x_{j}}\left[\left(\mu \lg +\frac{\mu_{t}}{\sigma_{k}}\right) \frac{\partial k}{\partial x_{j}}\right]+P_{k}-\beta^{\prime} \rho_{\lg } k \omega+P_{k b}
\end{aligned}
$$

$\omega$ - Equation:

$$
\begin{aligned}
& \frac{\partial(\rho \mid \mathrm{g} \omega)}{\partial t}+\frac{\partial}{\partial x_{j}}\left(\rho \mid \mathrm{g} U_{j} \omega\right) \\
& =\frac{\partial}{\partial x_{j}}\left[\left(\mu \mid \mathrm{g}+\frac{\mu_{t}}{\sigma_{\omega}}\right) \frac{\partial \omega}{\partial x_{j}}\right]+a \frac{\omega}{k} P_{k}-\beta \rho_{\lg } \omega^{2}+P_{\omega b}
\end{aligned}
$$

\section{Model Verification and Validation}

The above presented model has been examined and validated against reported experimental data. N. D. Patil et al. ${ }^{11}$, experimentally performed cooling studies in AHWR fuel assembly. One set of experimental data is used for validation test, data are shown in Table 1 . In order to

\begin{tabular}{|c|c|c|c|c|}
\hline \multicolumn{2}{|c|}{ Particular } & Experimental Data & \multicolumn{2}{|c|}{ Numerical Analysis } \\
\hline \multicolumn{2}{|c|}{ Initial Wall Temperature, (K) } & 430 & \multicolumn{2}{|c|}{430} \\
\hline \multicolumn{2}{|c|}{ Jet diameter, $(\mathrm{mm})$} & 2 & 2 & 3 \\
\hline \multirow{2}{*}{ Flow Rate } & Jets, $(\mathrm{kg} / \mathrm{s})$ & 0.016 & & 0.032 \\
\hline & Central Tube, (lpm) & 73 & & 150 \\
\hline \multicolumn{2}{|c|}{ Coolant Temperature, $(\mathrm{K})$} & 296 & & 296 \\
\hline \multicolumn{2}{|c|}{ Pressure condition } & \multicolumn{3}{|c|}{ Atmospheric } \\
\hline
\end{tabular}
perform the desired CFD simulations, the fluid domain discretized into various node numbers shown in Table 2. In addition, the first boundary layers are calculated

Table 1. Numerical data

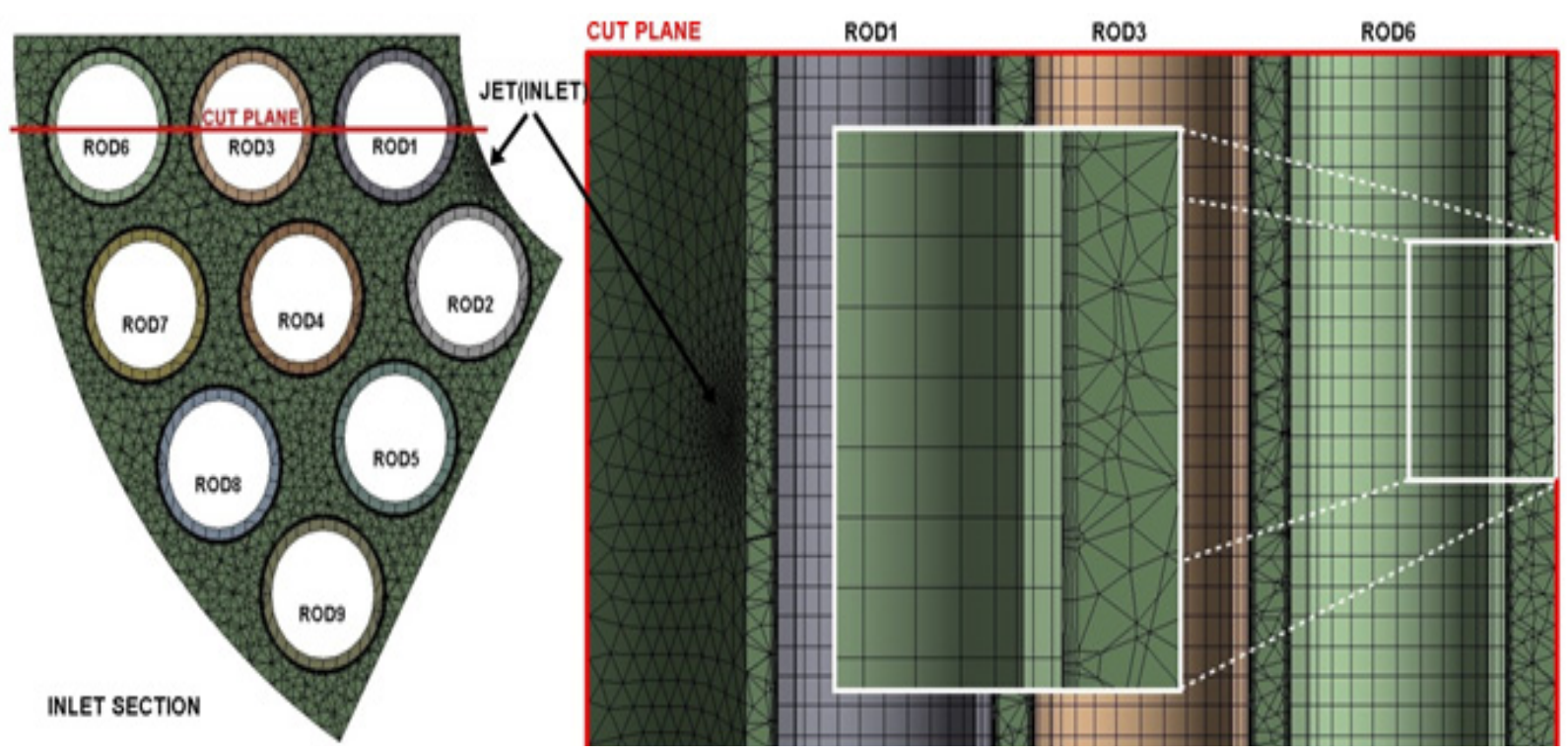

Figure 2. Physical structure of MESH3. 
Table 2. Characterization of mesh

\begin{tabular}{lcccc}
\hline Particular & MESH1 & MESH2 & MESH3 & MESH4 \\
\hline Number of nodes & 813909 & 1021814 & 1226644 & 1450909 \\
Number of elements & 1896838 & 2444263 & 2998971 & 3602225 \\
\hline
\end{tabular}

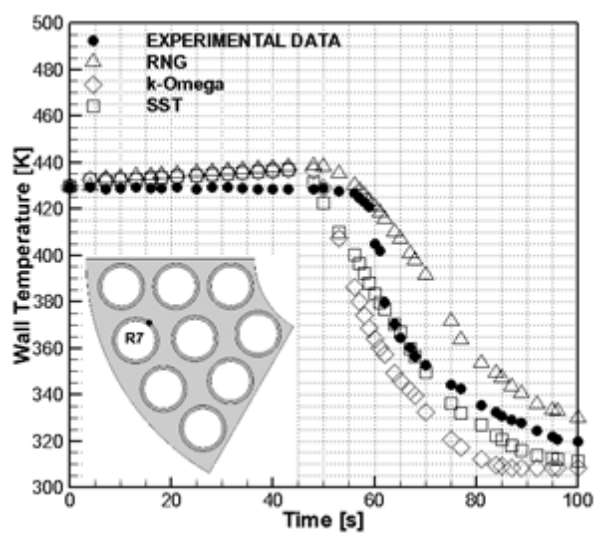

Figure 3. Numerical vs. experimental (Axial point, 235 $\mathrm{mm}$ ). [Jet diameter: $2 \mathrm{~mm}$; Initial wall temperature: $430 \mathrm{~K}$; Sub-cooled: 296K; Central flow rate: $73 \mathrm{lpm}$ ]

with maintaining the $y+$ value of 10 . The mesh stability calculation observed small variation after MESH3. Thus, the present investigation is emphasized with MESH3 as it ends to insensitivity. The physical structure of MESH3 is shown in Figure 2.

No-slip boundaries were applied on the surfaces of the rods. The unsteady simulation is conducted with the time step of one second and homogenous turbulence models with automatic wall function is employed. Numerical obtained results against reported experimental results are presented in Figure 3 and SST turbulence model shows good agreement with experimental data.

\section{Results and Discussion}

The rewetting process and cooling patterns in the rod bundle are observed from the wall temperature distribution. Figure 4 shows the contours of rod wall temperature. The results are observed at 70 second (Jet dia. $3 \mathrm{~mm}$ ). It is observed that the rewetting temperature is equal to the initial wall temperature in inlet section, which negligible wetting delay is observed. The high temperature gets to see in the upper section as well in the middle section. The contours wall temperatures are shown for one angular direction (see Figure 4, VIEW DIRECTION). Figure 5 describes the circumference of ROD1 wall temperature. The presented circumference

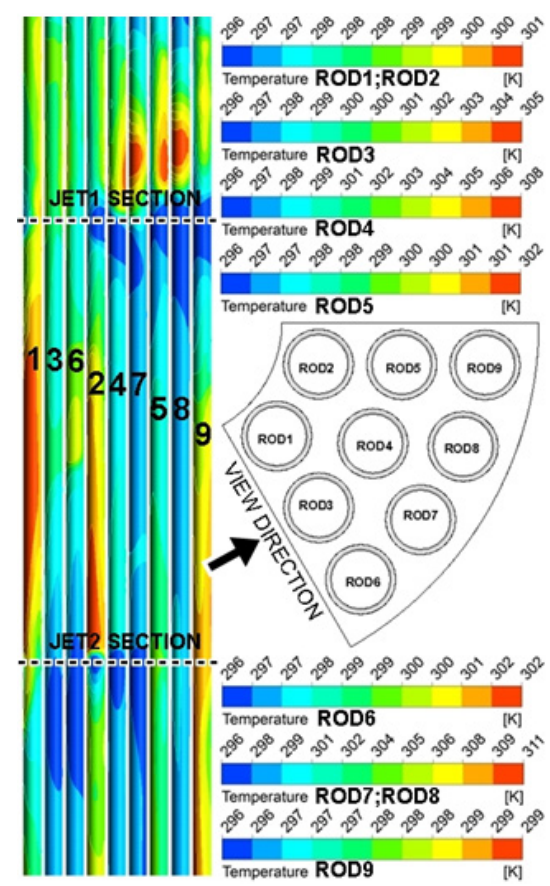

Figure 4. Wall temperature distribution (70 second).

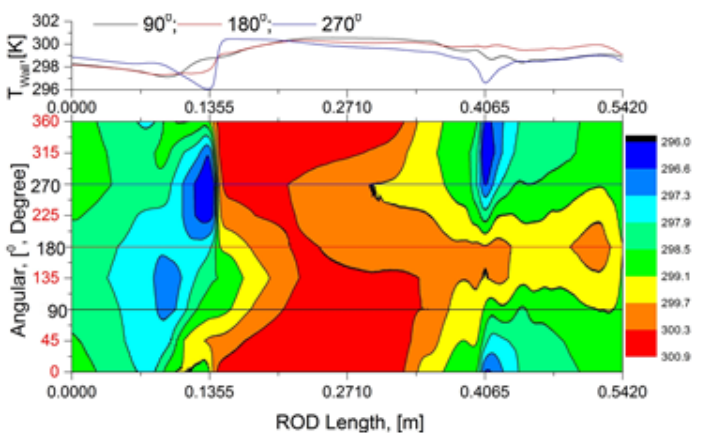

Figure 5. Circumference wall temperature of ROD1 (70 second).

contour wall temperature is drawn at time 70 second (Jet dia. $3 \mathrm{~mm}$ ). The details of angular points are presented in Figure 1 . Three lines (at $90^{\circ}, 180^{\circ}$ and $270^{\circ}$ ) are projected in a graph line.

The contours of cooling curve for ROD3 and ROD5 are shown in Figure 6. The data presented are from vertical points of ROD3 and ROD5 at angular $225^{\circ}$ and $90^{\circ}$ respectively. This data is evaluated for interest flow behavior in between two jets (JET1 and JET2). The jet is directed in different directions (JET1 between ROD4 and ROD5; JET2 between ROD4 and ROD3), thus coolant rewet hot rods in different manner for each different 
section of rod surfaces. In the case of ROD3, the wetting delay is negligible in JET2 section; similarly in ROD5 it is observed in JET1 section. This is due to the jet direction which large quantity of coolant gets to interact with the hot surface. Thus, in the vertical location away from the jet section is observed to be a longer wetting delay. The visualization of boiling regimes and rewetting progress are shown in Figure 6. The rewetting temperature can be tracked in the cooling contour following the boundary of contour line between yellow and green color (black dots).

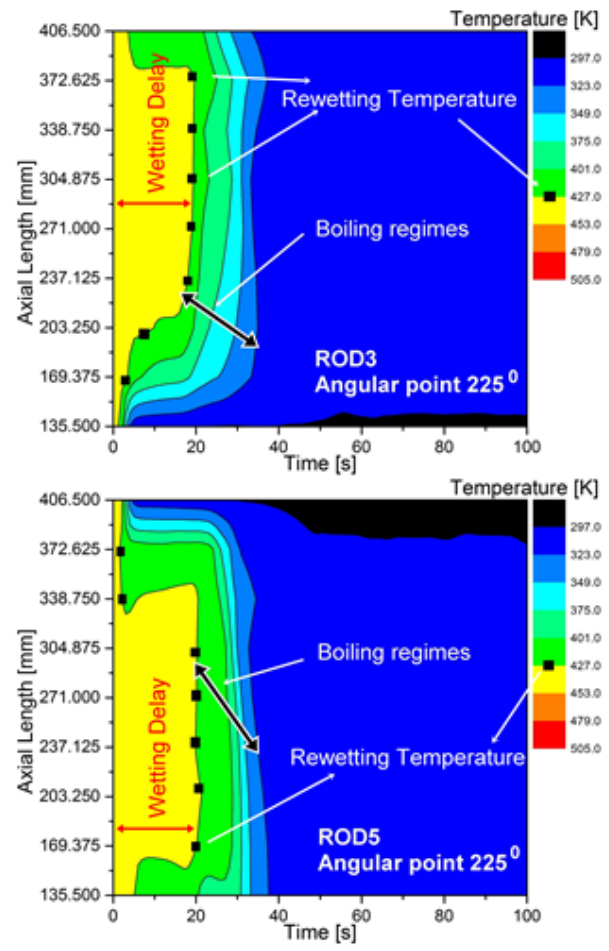

Figure 6. Contours of cooling curve (Jet dia. $3 \mathrm{~mm}$ ).

The effect of the jet diameters on rewetting progress is shown in Figure 7. The drawn cooling curve is from ROD4 at angular $180^{\circ}$ in respective to vertical position 203.25 $\mathrm{mm}, 271 \mathrm{~mm}$ and $338.75 \mathrm{~mm}$. The effect of jet diameter examines with three different diameters $(2 \mathrm{~mm}, 3 \mathrm{~mm}$ and $4 \mathrm{~mm}$ ). It is observed with increased in jet diameter the wall temperature and wetting delay reduce. Also rewetting temperature reduced with larger jet diameter. Merely it is seen small effect compared to smaller jet diameter. In smaller jet diameter the wetting delay as well as the wall temperature rises with large values. It is noted that the high heat up occurs with smaller jet diameter. Thus the rewetting temperature may turn up as peak wall temperature with smaller jet diameter. The water volume fraction and dry air (void) fraction for different jet diameters are shown in Figure 8.

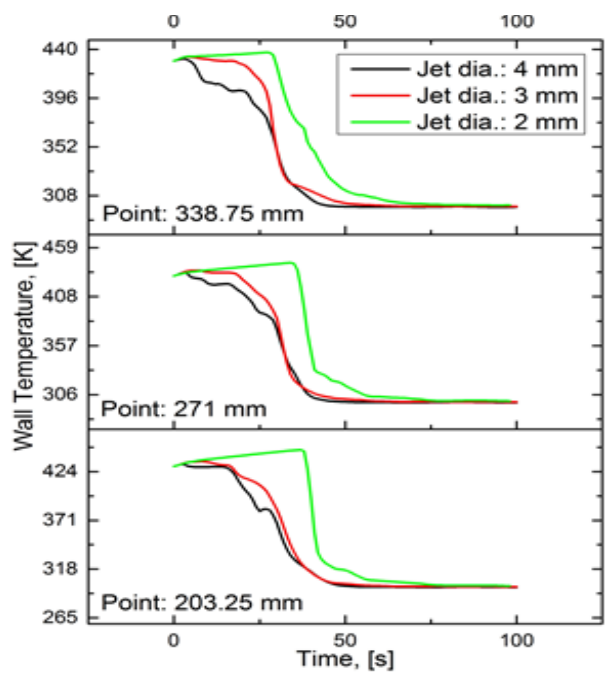

Figure 7. Cooling curve (ROD4; angular point $180^{\circ}$ ).

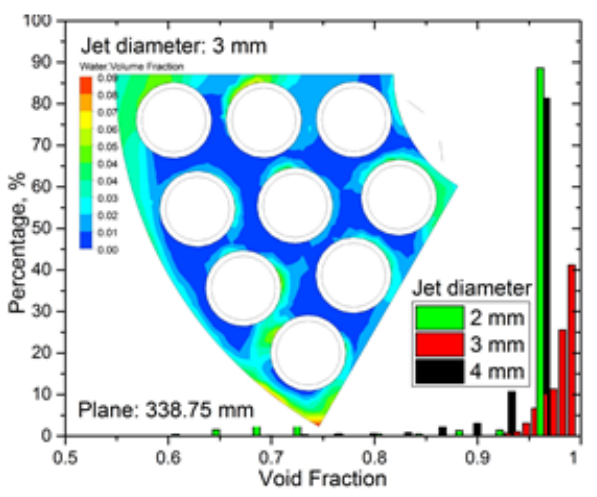

(a)

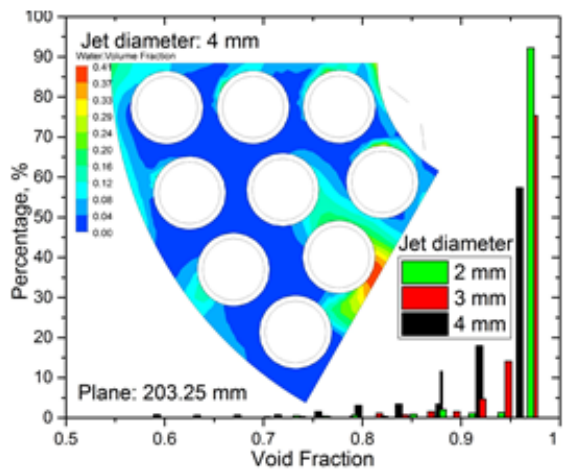

(b)

Figure 8. Water volume fraction and void fraction (Time $25 \mathrm{~s})$. 
The coolant water volume fraction for $3 \mathrm{~mm}$ jet diameter in plane $338.75 \mathrm{~mm}$ at 25 seconds are shown in Figure 8-a. It is seen that the void fraction are distributed in small percentages in several in between rod bundle. Nevertheless, with smaller jet diameters as well as with a larger jet diameter, the void fraction seen to be increased in some particular local zone. This can contribute to local peak wall temperature. Thus, the rewetting pattern is uneven and irregular due to the coolant flow behavior. The coolant water volume fraction for $4 \mathrm{~mm}$ jet diameter in plane $203.25 \mathrm{~mm}$ at 25 seconds are shown in Figure 8-b. The void fraction reduced with increased in jet diameter and increases with smaller jet diameter.

\begin{tabular}{|c|c|c|c|}
\hline \multicolumn{4}{|c|}{ Nomenclature } \\
\hline $\mathrm{r}$ & Volume phase fraction & & Greek symbols \\
\hline $\mathrm{U}$ & Vector of velocity $U_{x y z}$ & $\rho$ & Density \\
\hline $\mathrm{N}_{\mathrm{p}}$ & No. of phase & $\Gamma$ & Diffusivity \\
\hline $\mathrm{p}$ & Pressure & $\mu$ & Dynamic viscosity \\
\hline g & Gravity & $\lambda$ & Thermal conductivity \\
\hline $\mathrm{T}$ & Temperature & $\tau$ & Stress tensor \\
\hline M & Interfacial forces & $\mathrm{S}_{\mathrm{E}}$ & Energy source \\
\hline $\mathrm{e}$ & Internal energy & $\sigma_{\mathrm{k}}$ & Model constants \\
\hline Q & Heat flux & $\begin{array}{l}\sigma_{\omega} \\
\mu\end{array}$ & Saturated viscosity \\
\hline $\mathrm{h}$ & Heat transfer coefficient & $\omega$ & Turbulent frequency \\
\hline $\mathrm{k}$ & $\begin{array}{l}\text { Turbulence kinetic ener- } \\
\text { gy per unit mass }\end{array}$ & & \\
\hline $\mathrm{h}_{\mathrm{fg}}$ & $\begin{array}{l}\text { Latent heat of vapor- } \\
\text { ization }\end{array}$ & & Subscripts \\
\hline$c_{p}$ & Specific heat & a & $\begin{array}{l}\text { to indicate that the qual- } \\
\text { ity applies to phase a }\end{array}$ \\
\hline $\mathrm{D}_{\mathrm{o}}$ & Rod outer diameter & $\beta$ & $\begin{array}{l}\text { to indicate that the qual- } \\
\text { ity applies to phase } \beta\end{array}$ \\
\hline$\Delta \mathrm{T}$ & $\begin{array}{l}\mathrm{T}_{\mathrm{w}}-\text { Saturated tempera- } \\
\text { ture }\end{array}$ & s & surface \\
\hline $\mathrm{P}_{\mathrm{kb}}$ & $\begin{array}{l}\text { Buoyancy production } \\
\text { for k equation }\end{array}$ & $\mathrm{q}$ & Quenching \\
\hline \multirow[t]{3}{*}{$\mathrm{P}_{\omega \mathrm{b}}$} & Buoyancy production & $\mathrm{v}$ & Vapor \\
\hline & & 1 & Liquid \\
\hline & & $\mathrm{g}$ & gas \\
\hline
\end{tabular}

\section{Conclusion}

The rewetting behavior under various jet diameters with Zig-Zag jet direction have been examined with the help of ANSYS 14.0 CFX Solver code. The irregular wall temperature distribution was observed across vertical and the circumference of rod surfaces. Increased in jet diameter, the rewetting temperature and wetting delay reduce significantly. The rewetting temperature may locate as the local peak wall temperature at the location away from inlet section. It is also noted that the wetting delay is negligible at any inlet section.

From the previous survey report, the rewetting behavior is also influenced by mass flow, sub-cooled, initial wall temperature and so on. The present paper investigates only the influence of the jet direction and jet diameters on rewetting hot vertical rod bundle. Further works need to be studied with the above mentioned parameters.

\section{References}

1. Piggott BDG, White EP, Duffey RB. Wetting delay due to film and transition boiling on hot surfaces. Nuclear Engineering Design. 1976 Feb; 36(2):169-81.

2. Lee Y, Shen WQ. Effect of coolant vapor quality on rewetting phenomena. International Journal of Heat Mass Transfer. 1985 Jan; 28(1):139-46.

3. Barnea Y, Elias E, Shai I. Flow and heat transfer regimes during quenching of hot surfaces. International Journal of Heat Mass Transfer. 1994 Jul; 37(10):1441-53.

4. Mozumder AK, Monde M, Woodfield PL. Delay of wetting propagation during jet impingement quenching for a high temperature surface. International Journal of Heat Mass Transfer. 2005 Dec; 48(25-26):5395-407.

5. Hammad J, Mitsutake Y, Monde M. Movement of maximum heat flux and wetting front during quenching of hot cylindrical block. International Journal of Thermal Sciences. 2004 Aug; 43(8):743-52.

6. Hall DE, Incropera FP, Viskanta R. Jet impingement boiling from a circular free-surface jet during quenching: Part 1 - Two-Phase Jet. Journal of Heat Transfer. 2001; 123(5):901-10.

7. Hall DE, Incropera FP, Viskanta R. Jet impingement boiling from a circular free-surface jet during quenching: Part 2 - Two-Phase Jet. Journal of Heat Transfer. 2001; 123(5):911-7.

8. Agrawal C, Kumar R, Gupta A, Chatterjee B. Determination of rewetting on hot horizontal surface with water jet impingement through a sharp edge nozzle. International Journal of Thermal Sciences. 2013 Sep; 71:310-23. 
9. Agrawal C, Kumar R, Gupta A, Chatterjee B. Effect of jet diameter on the maximum surface heat flux during quenching of hot surface. Nuclear Engineering and Design. 2013 Dec; 265:727-36.

10. Sahu SK, Das PK, Bhattacharyya S. An experimental investigation on the quenching of a hot vertical heater by water injection at high flow rate. Nuclear Engineering Design. 2010 Jun; 240(6):1558-68.

11. Patil ND, Das PK, Bhattacharyya S, Sahu SK. An experimental assessment of cooling of a 54-rod bundle by in-bundle injection. Nuclear Engineering Design. 2012 Sep; 250:500-11.

12. Kumar M, Mukhopadhyay D, Ghosh AK, Kumar R. Study on Influence of Rewetting on Conduction Heat Transfer for AHWR Fuel Bundle Re-flooding Phenomena. International Journal of Nuclear Energy Science Engineering. 2013 Dec; 3(4):85-94.
13. Kumar M, Mukhopadhyay D, Ghosh AK, Kumar R. Numerical study on influence of cross flow on rewetting of AHWR fuel bundle. Scientific World Journal. 2014 Feb; (2014):1-10.

14. Debbarma A, Pandey K.M, NumericalAnalysis on the Effect of Flow Rates and Jet Diameter in Rewetting Vertical Nuclear Fuel Bundle with Jet Impingements. Annals of Nuclear Energy. 2016 Apr; 94:518-529.

15. Debbarma A, Pandey K.M, Influenceon rewetting temperature and wetting delay during rewetting rod bundle byvarious radialjet models. Kerntechnik. 2016 March; 81(1):50-59.

16. Sinha RK, Kakodkar A. Design and development of the AHWR - The Indian thorium fuelled innovative nuclear reactor. Nuclear Engineering Design. 2006 Apr; 236(78):683-700. 